Article

\title{
International Student Engagement for Sustainability of Leisure Participation: An Integrated Approach of Means-End Chain and Acculturation
}

\author{
Nahyun Lee ${ }^{1,2}$ and Bong-Seok Kim ${ }^{1, *(D)}$ \\ 1 Department of Convention \& Exhibition Management, Graduate School, Kyung Hee University, \\ Seoul 02447, Korea; nahyunlee10@gmail.com \\ 2 International Exchange of Education, Ministry of Education, National Institute for Intenational Education, \\ Seongnam-si 13557, Korea \\ * $\quad$ Correspondence: herz5@khu.ac.kr; Tel.: +82-2-961-0866
}

check for updates

Citation: Lee, N.; Kim, B.-S.

International Student Engagement for Sustainability of Leisure Participation An Integrated Approach of Means-End Chain and Acculturation. Sustainability 2021, 13, 4507. https:// doi.org/10.3390/su13084507

Academic Editor: Marta Soler

Received: 27 February 2021

Accepted: 16 April 2021

Published: 18 April 2021

Publisher's Note: MDPI stays neutral with regard to jurisdictional claims in published maps and institutional affiliations.

Copyright: (c) 2021 by the authors. Licensee MDPI, Basel, Switzerland. This article is an open access article distributed under the terms and conditions of the Creative Commons Attribution (CC BY) license (https:/ / creativecommons.org/licenses/by/ $4.0 /)$.

\begin{abstract}
This study examined international students' engagement in leisure activities using data derived from an integrated method and analyzed through acculturation and means-end chain approaches. A cluster analysis was conducted to identify acculturation types. An initial qualitative survey with 30 respondents produced the questionnaire items, and a quantitative survey to construct value maps was conducted targeting 415 respondents. The cluster analysis identified bicultural acceptance, heritage culture maintenance, and bicultural marginalization as distinct types that distinguish the acculturation level among international students. The results from three acculturation types indicate that the significant items and strong linkages between attribute-consequence and consequence-value at each level reflect the international students' inner thoughts and ultimate value. Such strong associations provide value maps, which differ according to the acculturation types. Such findings present that availability of leisure services is necessary to better cater to the special interests of international students at different stages of acculturation. Given that international student mobility has increased substantially, relevant leisure professionals and organizations should understand that international students' sustainable leisure engagement can only be achieved if attention is paid to cultural contexts.
\end{abstract}

Keywords: acculturation; international students; Means-end chain; leisure activities; hierarchical value map

\section{Introduction}

Leisure is an opportunity to improve one's quality of life and well-being. One's leisure lifestyle represents one unique value and interprets one relationship to the customs within the culture [1]. It is not just time spent being idle, leisure is also recognized as a meaningful time to develop the skills and competencies desired for personal achievement and creation [2,3]. Even though such positive impacts of leisure participation are widely acknowledged, cultural similarities and differences in leisure practices may exist across types of leisure activity [4-6]. For instance, attending sporting events was positively related to Canadian students' family happiness for the predominant culture in Northern America. However, outdoor recreation activities may provide Chinese students with opportunities to partake in the activities, which subsequently contribute to their life satisfaction [4]. When it comes to leisure activities [5], Canadians had significantly higher cognitive, affective, and behavioral leisure attitudes than those of Mainland Chinese; whereas, Chinese in Canada reported significantly less positive cognitive and affective leisure attitudes than AngloCanadians, although their behavioral attitudes did not significantly differ [6]. Hence, without considering the cultural context, leisure practitioners can unknowingly harm participants instead of helping them experience leisure benefits [7]. 
International students are considered as a group with diverse ethnic and racial backgrounds and face many challenges while studying in foreign countries. Engaging in leisure activities can reduce negative feelings and decrease school-related stress for students [8], promoting and enhancing daily emotional well-being [9]. Some international students suffer from depression and anxiety due to the stress of studying abroad, such as language barriers, financial difficulties, tuition, living expenses, and difficulties in their daily lives [10]. The proper participation of international students in leisure activities is considered an effective way to relieve the cultural stress or psychological difficulties of contacting, adapting, and experiencing these new cultures [11,12]. Participation in leisure activities for international students is a positive and effective way to improve academic performance and achieve the purpose of studying abroad by providing opportunities for friendship formation and school adaptation $[13,14]$.

Contrary to prior research, if the level of acculturation of international students is low, exposure to other cultures encountered through leisure activities can be recognized as discrimination, and participation does not necessarily positively impact acculturation [15,16]. Such adaptation challenges may occur in leisure constraints. According to Tsai [17], more acculturated individuals perceive fewer leisure constraints [18], indicating that they have higher levels of socio-cultural, interpersonal, and access constraints. Similarly, immigrants who were more acculturated tend to have a lower level of socio-cultural constraints, access constraints, and interpersonal constraints. In contrast, less marginalized groups tend to have a lower level of access constraints, and affective constraints, regardless of their acculturation levels [19]. Therefore, leisure constraints serve as inhibitors of participants leisure involvement [20].

Consequently, the level of acculturation is an essential variable in explaining leisure participation for individuals of different cultural backgrounds [21,22]. Multiple studies have stressed the importance of understanding relationships between acculturation and leisure participation for international students as participation in leisure activities affects behavioral and cultural value acculturation $[13,14,23]$. Despite the importance of acculturation associated with leisure engagement, a limited research volume exists on why they participate in leisure activities and what values they want to gain among international students. Thus, the current study seeks to identify the value structure for leisure activities based on the acculturation of international students who participate in leisure activities and then compare the leisure value structure by acculturation types. Means-end chain (MEC) analysis was employed to construct a hierarchical value map (HVM) to illustrate international students' cognitive structure of leisure participation [24,25]. Building on earlier work by Berry's [26] bidimensional acculturation, the Vancouver Index of Acculturation (VIA) has been verified to be a useful measurement for international students with different cultural backgrounds. Therefore, this study, using an integrated approach, explores how the level of acculturation impacts the personal values of international students with regard to leisure activities.

The purposes of this study are (1) to identify the types of acculturation for international students based on the level of acculturation; (2) to investigate attributes, consequences, and values intent towards leisure participation; (3) to analyze the associations between linkages on each acculturation type and construct a hierarchical value map based on the level of association; and (4) to provide practical implications for universities and organizations to make international student mobility sustainable in higher education.

\section{Theoretical Background}

\subsection{Acculturation of International Students}

Cultural adaptation is a phenomenon that occurs when groups of different cultures are frequently in contact with each other [27]. Early cultural adaptation studies described immigrants' forms of cultural adaptation in a straight line from the perspective of bipolar acculturation, with one end representing the value of their heritage culture. The other is the value of the mainstream culture of the migrant country [28]. Thus, a higher value on 
one side reduces value on the other, and the middle point of continuity is described as biculturalism, which values both cultures [29]. However, it has been criticized that viewing cultural adaptation as a single dimension lacks an explanation for the immigration attitude of both cultures and the increase in immigration phenomena [30].

Contrary to these findings, the study by Berry [21] approached the process of cultural adaptation in two dimensions. The study categorized it into four outcomes based on answers to two-dimensional questions about maintaining one's cultural values and characteristics or maintaining relationships with mainstream society. The study has shown that immigrants in multicultural societies utilize one of four acculturation strategies: assimilation, separation, integration, or marginalization. Assimilation refers to giving up one's cultural identity and moving into a larger society. Separation involves maintaining ethnic identity and traditions and a simultaneous absence of relations with the larger society. Integration constitutes the maintenance of a group's cultural integrity while simultaneously becoming an integral part of the larger society. Marginalization happens when individuals have no cultural or psychological contact with their traditional culture or the larger society [31]. The four types of cultural adaptation presented by Berry [21] have been used in various acculturation studies for foreigners, serving as the foundation of many studies.

When it comes to measuring acculturation, the study of Barry [26] found that The East Asian Acculturation Measure (EAAM) scales, which is widely used to measure the type of cultural adaptation among Asian students, can be measured according to attitudes and behavioral aspects of social contact, communication skills, and ease. The EAAM is a 29-item self-report inventory, which measures four dimensions of acculturation based on Berry [27], and has been employed as a useful tool to investigate East Asia's acculturation patterns. In related literature, Ryder et al. [32] constructed the Vancouver Index of Acculturation (VIA) as a psychometrically sound bidimensional acculturation measure. It suggests that the scale can be measured using concepts commonly extracted as cultural adaptation elements in existing prior studies, such as the degree of importance to mainstream and heritage culture values, interactions and social relationships between groups, preference for cultural, social celebrations, and language proficiency [33]. The VIA, a self-report instrument that evaluates several domains relevant to acculturation, permitting a more decisive evaluation of the two dimensions. The VIA, a psychometrically sound bidimensional acculturation measure, has been employed in several studies involving participants from different cultural groups, countries of origin, and receiving countries [32,34].

The use of acculturation measures has yielded promising results in understanding the cultural adaptation of international students. According to the acculturative level, Kim [35] carried out a study of international students studying in Korea, comparing acculturative factors and strategies. Strategies for each level of acculturation were shown in the order of marginalization, separation, assimilation, and integration among the high, middle, and low groups. That reveals that the longer the period of stay, the less separation and marginalization occur, and the greater the degree of assimilation or integration into the new culture. Cao et al. [36] found that acculturation can also appear differently within the same group. According to the study results, which studied cultural adaptation strategies for Chinese students studying abroad, the same Chinese student shows that acculturation strategies vary depending on his residence environment. Students studying in Belgium used an integrated strategy to maintain both local and domestic cultures, whereas Chinese students in Australia were adapted to the local area using different strategies. Students staying in Canada, however, were found to prefer an integrated strategy. It is explained that different outcomes within these groups are influenced by personal characteristics, cultural distance from their own culture and mainstream culture, and mainstream countries' views and attitudes toward their people.

\subsection{Leisure for International Students}

Participation in leisure activities positively impacts cultural adaptation through immigrants' inclusion in new leisure activities and increased interpersonal experience and 
cultural understanding [37]. For international students, leisure time can lead to cultural learning and acceptance, relief, and healing caused by cultural adaptation stress, and a support system can be formed through sharing. Thus, students who participate in leisure activities are better adapted to studying abroad [38,39]. The characteristics of leisure activities resulting from these cultural adaptations vary from group to group and from type to type of acculturation. The preferences and forms of participation in leisure activities are different in different races and cultural backgrounds [40]. However, even in groups with the same cultural backgrounds, ethnicity, and race, acculturation appears differently and participates in leisure activities based on acculturation types [41]. Besides, leisure activities and leisure attitudes vary depending on the type of acculturation [42].

Leisure plays an influential role in social and cultural adaptation for international students, enabling them to experience the culture while learning about the host country [43]. This means that international students' participation in leisure activities positively impacts their adaptation to their society and their adaptation to school life [38]. In related literature, Lu et al. [10] have shown that leisure is a vital variable in cultural and academic adaptation, as it plays a positive role in learning and adapting to the culture of the host country and relieving stress for international students. Lian and Yang [44] carried out a study of 258 Chinese international students in Korea. The study found that participation in leisure activities provides positive changes to students' satisfaction in school life, psychological comfort, and mental health, affecting school adaptation and college satisfaction. Additionally, students' participation in leisure activities has a more significant impact on social adaptation, personal and emotional adaptation, and college life adaptation than studying itself.

\subsection{Relationship between the MEC Theory and Leisure}

The Means-End Chain (MEC) theory, proposed by Gutman [45], describes the consumer's cognitive structure of how products and consumer values are linked and focused on personal consumer value to fulfill the desired end state. It focuses on the link between the desired ends of consumers' values and the means to the subjective perception of the features of products or services perceived by consumers. It aims to structure consumers' cognitive processes in attributes, consequences, and values levels and identify their relationships [46]. The MEC theory has been adopted to understand consumers' decision-making process in the marketing domain [47]. Recent studies have started to use MEC in leisure to examine consumers' decision-making behavior [48]. This approach has been widely utilized to elicit what attributes of the leisure activities are most suitable to participants, how participants' motivations are related to each other, and what personal values are behind the motivations that participants pursue [49].

Research by Lopez et al. [50] has shown how benefits and attributes affect personal values and how they relate to peri-urban greenspaces users' monetary values. The results show that the higher the value of users in using the space, the more willing they are to pay for the admission fee. Jiang [51] used MEC-based laddering interviews of 60 Chinese outbound leisure tourists to examine motivations and their relationship to Chinese cultural values. These cultural values affect how and why Chinese tourists travel abroad, meaning that tourists' motivations are caused by the cultural values of their native culture. Hong [52] found that the leisure value pursued varies depending on the participants' age in leisure activities. A survey targeting 112 yoga trainees about the value of leisure activities by age group indicates that the values pursued by yoga trainees in their 20s were found to be happiness, the vitality of life, and leisurely life, while the values pursued by yoga trainees in their 30s were shown to be the vitality of life and pleasure. The values of those in their 40s were shown to be vitality and happiness in their lives throughout the Yoga training. Kim [53] carried out a study of the leisure value system according to the type of participation in leisure activities. The types of leisure activity were divided into six, and the value pursued through participation was different depending on the types of leisure activity. The value of each type of leisure activity was shown to be different, but 
for all leisure activity participants, the factor of happiness was considered as the most important value. Previous studies indicated that the use of MEC has yielded good results in the construction of a cognitive structure for leisure participants [54]. However, very few studies have adopted MEC to understand it in a cross-cultural context. The purpose of this study is to extend MEC to the domain of cross-cultural leisure study, which suggests that a fuller understanding of the relationship between acculturation and personal values can be achieved if attention is paid to cultural contexts.

\section{Materials and Methods}

Integrating the MEC and acculturation theories, this study explores how participants' perceptions of leisure activities are formed according to their acculturation types. In the current study, qualitative and quantitative methods were employed; thus, data were collected by three stages. In the first stage, the quantitative method was utilized to collect data to examine international students' acculturation types. In the second stage, the qualitative method, an in-depth interview, was conducted to identify the questionnaire design variables. In the last stage, a questionnaire survey was utilized for MEC analysis.

\subsection{Research Instrument}

The VIA is a 20-item instrument that measures orientations towards heritage and mainstream cultural groups and assesses several domains relevant to acculturation, including values, social relationships, and adhesion to cultural norms [55]. The item statements are general rather than established for specific target groups, generating in pairs concerning the content area. One item in each pair refers to the mainstream culture, and the other mirror item refers to the heritage culture. A list of VIA items is comprised of 10 heritage and ten mainstream items. Each item was rated on a 9-point Likert-type scale ranging from strongly disagree, disagree, disagree somewhat, neutral, agree somewhat, agree, strongly agree. The total score is derived by summing reverse and positive scored items. Examples of items include "I am comfortable working with people of the same native culture as myself." and I am interested in having typical Korean friends." Thus, high scores on each item subscale represent a positive orientation toward the culture represented [32].

\subsection{Laddering Methodology}

For the choice of data collection methods for the MEC analysis, laddering interview is the most widely known technique for guiding respondents to share their innermost thinking via a multistage cognitive structure concerning their behavior pattern [56,57]. There are two possible approaches of laddering techniques: soft laddering and hard laddering [58]. Soft laddering refers to in-depth one-on-one interviews, allowing respondents to give unrestricted answers. This method enables the researcher to understand the links or ladders between a product's attributes, consequences, and values, based on a series of progressive and iterative questions [59]. Hard laddering refers to laddering of structured questionnaire methods developed to be quicker and cheaper than soft laddering, placing less pressure on the respondents $[60,61]$. This approach is conducive to large samples (more than 50 subjects). Thus, it is suitable for market segmentation studies and is often used in comparative cultural studies [62]. In addition, hard laddering distinguishes itself from soft laddering, which employs in-depth interviews where respondents are minimally limited [63].

The technique used in the case in hand is the Association Pattern Technique (APT) as a quantitatively oriented approach to assessing means-end chains conceived as a series of connected matrices [45]. In APT, an AC-matrix (attribute-consequence matrix) and a CV-matrix (consequence-value matrix) are distinguished. For each column in the ACmatrix (CV-Matrix), respondents indicate to which consequences (values) that attribute (consequence) is considered to lead [64]. Despite these differences, both approaches analyze the meaning of the answers, develop a mean-end model [65], and means-end chain studies using both soft and hard laddering techniques to provide very similar results [66]. 


\subsection{Contents Analysis}

A laddering interview was adopted as a qualitative method to design a questionnaire: the elicitation of critical attributes and the in-depth interview [45]. Respondents are required to compare and evaluate the significant attributes revealed as the starting point for the interview, where respondents need to explain the relationship between the consequences and their values. The in-depth interview where respondents are asked to explain their relevance concerning the perceived associated consequences and values and interviewers ask respondents repeatedly, "why is that important to you?" until they are no longer able to answer [67]. This study adopted the laddering technique to collect data by interviewing 30 international students studying in Korea to participate in leisure activities. They came from a variety of countries: 14 from Northeast Asia (e.g., China, Japan, Mongolia), eight from Southeast Asia (e.g., Vietnam, Philippines, Cambodia, Malaysia, Myanmar), three from Central Asia (e.g., Kazakhstan, Uzbekistan, Pakistan), two from Europe (e.g., Germany, France), two from America (e.g., U.S.A., Brazil), one from Kenya. All respondents are in a degree program (e.g., Bachelor, Master, Doctoral), living in Korea for five years on average.

Each respondent is required to answer the following questions: what attributes (A) of leisure activities did they consider important and why? What benefits or consequences (C) did they gain after experiencing these attributes? What values $(\mathrm{V})$ did they achieve through these consequences? The content analysis produced a total of 37 variables, comprising 13 attributes $(\mathrm{A})$, eight functional consequences $(\mathrm{F})$, eight psychological consequences $(\mathrm{P})$, and eight values (V) (see Table 1).

Table 1. Classification of the Attributes, Consequences, and Values used in this study.

\begin{tabular}{|c|c|c|c|}
\hline Attributes & $\begin{array}{l}\text { Functional } \\
\text { Consequences }\end{array}$ & $\begin{array}{l}\text { Psychological } \\
\text { Consequences }\end{array}$ & Values \\
\hline A1 learning Korean & F1 maintaining a friendship & P1 feeling pleasure & V1 happiness \\
\hline $\begin{array}{l}\text { A2 Improving psychological } \\
\text { strength }\end{array}$ & F2 vital life energy & $\mathrm{P} 2$ reducing anxiety & V2 a state of balance \\
\hline $\begin{array}{l}\text { A3 understanding Korean } \\
\text { culture }\end{array}$ & F3 feeling physically better & P3 understating others & V3 a sense of accomplishment \\
\hline A4 building a human network & F4 economic benefits & P4 a boost in confidence & V4 improving social skills \\
\hline A5 staff service & F5 a better understanding of Korea & P5 refreshing myself & V5 the value of life \\
\hline A6 facility quality & F6 a new try & P6 reducing stress & V6 self-reward \\
\hline A7 self-improvement & F7 improving my ability & P7 self-satisfaction & V7 healthy \\
\hline A8 escaping daily life & F8 building a positive image of me & P8 a bond of sympathy & V8 self-assurance \\
\hline \multicolumn{4}{|l|}{ A9 relaxing } \\
\hline \multicolumn{4}{|l|}{ A10 various experiences in } \\
\hline \multicolumn{4}{|l|}{ Korea } \\
\hline \multicolumn{4}{|l|}{ A11 releasing stress } \\
\hline \multirow{2}{*}{\multicolumn{4}{|c|}{$\begin{array}{l}\text { A12 sharing my heritage } \\
\text { culture }\end{array}$}} \\
\hline & & & \\
\hline A13 killing time & & & \\
\hline
\end{tabular}

The whole questionnaire consisted of three parts: the quantitative (hard laddering) method to assess MEC, acculturation types, and socio-demographic information. The version of the APT used in this study consists of three independent matrices, and all produced variables which were listed in the columns and rows, respectively: An A-F matrix (attributefunctional consequence), an F-P matrix (functional-psychological consequence), and a P-V matrix (psychological consequence-value) [68]. Each respondent could choose one to three items for each A/F/P/V level. The Vancouver Index of Acculturation, a 9-point Likert-type scale, was adopted to investigate the respondents' acculturation dimensions. The last part of the questionnaire was designed to collect the respondents' socio-demographic characteristics such as gender, program of study, length of residence, Korean language proficiency, age, and nationality. In order to improve validity and make a user-friendly questionnaire, 
the pilot study was extensively conducted in a series of meetings with experts (staff in charge of international students in university) and focus groups. They suggested minor adjustments to make it clear and readable for international students.

Consequently, the finalized questionnaire was sent consisting of the research outline and website link, which hosted the questionnaire [69]. The survey was conducted for 500 international students currently participating in leisure activities. Of the 500 questionnaires distributed, 478 surveys were returned for a response rate of $95 \%$. The number of valid samples was 415, after eliminating 63 incomplete or missing data questionnaires.

\section{Results}

\subsection{Description of Participants}

Within the 415 international student sample, $59.8 \%$ were females, and $40.2 \%$ were males. The respondents were in Master's degree (38.6\%) or Bachelors' degree (25.8\%), aged between 25 and $30(47.2 \%)$, or 18 and $24(41.7 \%)$. The majority of students came from Northeast Asia (51.8\%), obtaining level $4-5$ of TOPIK (46.7\%). The length of residence in Korea ranged from 1 to $<3$ years takes $47 \%$ of respondents, and $61 \%$ indicated that they stayed in a metropolitan area (61\%) (see Table 2).

Table 2. Characteristics of the survey respondents $(n=415)$.

\begin{tabular}{|c|c|c|c|c|c|}
\hline Characteristics & $n$ & $\%$ & Characteristics & $n$ & $\%$ \\
\hline Gender & & & Age & & \\
\hline Male & 167 & 40.2 & $18-24$ & 173 & 41.7 \\
\hline Female & 248 & 59.8 & $25-30$ & 196 & 47.2 \\
\hline Nationality & & & $31-36$ & 37 & 8.9 \\
\hline Northeast Asia & 215 & 51.8 & Over 37 & 9 & 2.2 \\
\hline Southeast Asia & 82 & 19.5 & Program of study & & \\
\hline Central Asia & 42 & 10.1 & BA & 107 & 25.8 \\
\hline Europe & 40 & 9.6 & MA & 160 & 38.6 \\
\hline America & 22 & 5.3 & Doctoral & 52 & 12.5 \\
\hline Africa & 14 & 3.4 & Language & 96 & 23.1 \\
\hline $\begin{array}{l}\text { Length of residence } \\
0 \text { to }<1 \text { vear }\end{array}$ & 110 & 26.5 & Test of Proficiency in Korean (TOPIK) & & \\
\hline 1 to $<3$ years & 195 & 47.0 & None & 42 & 10.1 \\
\hline 3 to $<5$ years & 91 & 21.9 & Level 1-3 & 85 & 20.5 \\
\hline $5+$ years & 19 & 4.6 & Level 4-5 & 194 & 46.7 \\
\hline Region & & & Level 6 & 94 & 22.7 \\
\hline Metropolitan area & 253 & 61.0 & & & \\
\hline Non-metropolitan area & 162 & 39.0 & & & \\
\hline
\end{tabular}

\subsection{Three Types of Acculturation}

The instrument used in this study to evaluate the heritage and mainstream dimensions of acculturation is the scale developed by Ryder et al. [34]. According to the scale, 20 items were generated in pairs, with one item referring to the mainstream culture and the other item referring to the heritage culture. The exploratory factor analysis (EFA) was utilized, with principal component analysis to check the factor structure. Exploratory factor analyses with varimax rotation were conducted to examine the factor structure underlying the scale of VIA. The method was done to validate whether the respondents perceived the independent, mediating, and dependent variables were distinct constructs. Representativeness was good $(\mathrm{KMO}=0.905)$ and Bartlett's sphericity test was significant $\left(\chi^{2}=2648.946, p<0.001\right)$. The commonalities lower than 0.35 , as suggested by Igbaria et al. [70], were extracted from further analysis. As a result, the VIA version used in this study is a 12-item instrument designed to measure the heritage and mainstream dimensions of acculturation [32,71], generating a two factor solution with eigenvalues greater than 1.0, and the total variance indicated $62.316 \%$. The items loaded onto factor 1 were labeled 
as heritage culture maintenance, and factor 2 as Korean culture acceptance, as shown in Table 3.

Table 3. Descriptive of the Major Factors with corresponding Reliabilities.

\begin{tabular}{ccccc}
\hline Factors & N. of Item & Mean & Std. & $\alpha$ \\
\hline Heritage culture maintenance & 6 & 5.179 & 0.545 & 0.884 \\
Korean culture acceptance & 6 & 4.598 & 0.434 & 0.865 \\
\hline
\end{tabular}

A cluster analysis, a hierarchical clustering analysis, was utilized to apply the stopping rule to determine the number of clusters where homogeneity of clusters is increasing relatively significantly. Then, the k-means method was conducted and produced clusters divided into three by theoretical assumptions. Building from the foundation of Berry's bidimensional acculturation model [26], we divided international students' acculturation strategies into three types: bicultural acceptance, heritage culture maintenance, bicultural marginalization. On average, respondents scored higher on heritage culture maintenance $(M=5.79)$ than Korean culture acceptance $(M=5.37)$, and the difference between means was statistically significant, $p<0.001$ (see Table 4).

Table 4. Cluster Analysis of Acculturation types.

\begin{tabular}{|c|c|c|c|c|c|}
\hline \multirow[t]{2}{*}{ Dimension } & $\begin{array}{c}\text { Bicultural } \\
\text { Acceptance }\end{array}$ & $\begin{array}{c}\text { Heritage Culture } \\
\text { Maintenance }\end{array}$ & $\begin{array}{c}\text { Bicultural } \\
\text { Marginalization }\end{array}$ & Total & $F$ \\
\hline & $n=171$ & $n=182$ & $n=62$ & $n=415$ & \\
\hline Heritage culture maintenance & 5.27 & 7.29 & 2.87 & 5.79 & $539.013 * * *$ \\
\hline Korean culture acceptance & 5.20 & 6.48 & 2.59 & 5.37 & $339.510 * * *$ \\
\hline
\end{tabular}

$* * * p<0.001$, Wilks' Lamda $=0.138, F=348.291, \mathrm{df}=4(p=0.000)$.

\subsection{Implication Matrix}

The hard laddering data were analyzed by using an implication matrix. It displays the number of times respondents directly or indirectly elicited each of the coded items and connections between attributes, consequences, and values [67]. Constructing the implication matrix is an essential tool for integrating the frequencies of association, and the figures provide the basis for constructing the Hierarchical Value Map (HVM). Building an HVM based on an implication matrix involves selecting a cut-off point to determine which relations should be represented on the map and which should not. All the linkages in the implication matrix could not be represented in a single HVM because the map would be too complicated to read. Thus, the idea in selecting a cut-off point is to select a value capturing the dominant relations displayed in the matrix [72].

The core concept of cut-off determination is to utilize a relatively small number of cells in the implication matrix to show a large portion of the total number of linkages [48]. The higher the frequencies of linkages, the more important are the linkages represented; thus, setting a cut-off point is recommended before HVM construction [25,73]. Dominant linkages were identified, as shown in the Table below. The matrix displays direct implications between the constructs to investigate each crucial item and ladder on levels [74]. The figures within the matrix show the frequency of the linkages, indicating the strength of the chain link between the factors based on the predetermined cut-off points on each acculturation type. The bold fonts represent the strong linkages detailing the direct associations between the constructs on different levels. Three to four of all items were selected at each level in order of frequency of responses.

\subsubsection{Bicultural Acceptance}

Regarding the frequencies of A-C linkage, learning Korean-improving my ability (83 times) accounts for the strongest linkage, followed by Understanding Korean culture- 
better understanding of Korea (57 times). For the F-P linkage, improving my abilityfeeling pleasure ( 85 times) was most frequently cited, followed by a better understanding of Korea-understanding others (61 times). From the P-V linkage, feeling pleasurehappiness (119 times) was the most frequently mentioned, followed by understanding others-improving social skills (58 times) (see Table 5).

Table 5. Implication Matrix of Leisure Activity Participants (Bicultural Acceptance).

\begin{tabular}{ccccccccccc}
\hline & F1 & F3 & F5 & F7 & P1 & P3 & P7 & V1 & V3 & V4 \\
\hline A1 & $\mathbf{3 4}$ & 5 & $\mathbf{4 1}$ & $\mathbf{8 3}$ & & & & & & \\
A2 & 6 & $\mathbf{2 5}$ & 1 & 10 & & & & & & \\
A3 & 8 & 2 & $\mathbf{5 7}$ & 11 & & & & & & \\
A7 & 11 & 11 & 3 & $\mathbf{3 2}$ & & & & & & \\
F1 & & & & & $\mathbf{4 0}$ & $\mathbf{4 3}$ & 9 & & & \\
F3 & & & & & $\mathbf{2 3}$ & 2 & 11 & & & \\
F5 & & & & & $\mathbf{3 9}$ & 61 & 10 & & & \\
F7 & & & & & & & 55 & $\mathbf{1 1 9}$ & 12 & $\mathbf{2 3}$ \\
P1 & & & & & & & & 21 & 14 & $\mathbf{5 8}$ \\
P3 & & & & & & & & $\mathbf{4 4}$ & $\mathbf{3 2}$ & 15 \\
P7 & & & & & & &
\end{tabular}

Note. Attributes (A): 1. Learning Korean 2. Improving physical strength 3. Understanding Korean culture 7 . Self-improvement/Functional consequences (F): 1. Maintaining a friendship 3. Feeling physically better 5. A better understanding of Korea 7. Improving my ability/Psychological consequences (P): 1. Feeling pleasure 3 Understanding others 7. Self-satisfaction/Values (V): 1. Happiness 3. A sense of accomplishment 4. Improving social skills; Strong linkages are represented in bold letters.

\subsubsection{Heritage Culture Maintenance}

In the case of A-C linkage, the relationship between self-improvement and improving my ability showed the strongest connection (96 times), followed by learning Korean and a better understanding of Korea with a higher connection (58 times). For the F-P linkage, a connection between improving my ability and self-satisfaction (61 times) was the most frequently mentioned, followed by a better understanding of Korea and understanding others (50 times). From the P-V linkage, self-satisfaction and a sense of accomplishment (88 times) account for the strongest linkage, followed by understating others and improving social skills (55 times) (see Table 6).

Table 6. Implication Matrix of Leisure Activity Participants (Heritage Culture Maintenance).

\begin{tabular}{cccccccccccccc}
\hline & F1 & F3 & F5 & F7 & F8 & P1 & P3 & P4 & P7 & V1 & V3 & V4 & V5 \\
\hline A1 & 16 & 6 & $\mathbf{5 8}$ & $\mathbf{5 2}$ & 6 & & & & & & & & \\
A2 & 4 & $\mathbf{2 8}$ & 1 & 9 & 13 & & & & & & & & \\
A4 & $\mathbf{2 9}$ & 4 & 8 & 2 & 7 & & & & & & & & \\
A7 & 18 & 7 & 4 & $\mathbf{9 6}$ & $\mathbf{2 9}$ & & & & & & & & \\
F1 & & & & & & $\mathbf{4 1}$ & 37 & 7 & 6 & & & & \\
F3 & & & & & & $\mathbf{2 4}$ & 4 & 14 & 13 & & & & \\
F5 & & & & & & $\mathbf{4 7}$ & $\mathbf{5 0}$ & 10 & $\mathbf{2 4}$ & & & & \\
F7 & & & & & & 14 & 2 & 14 & $\mathbf{4 0}$ & & & & \\
F8 & & & & & & & & & & $\mathbf{3 6}$ & 17 & 14 & $\mathbf{2 6}$ \\
P1 & & & & & & & & & & $\mathbf{2 5}$ & 16 & $\mathbf{5 5}$ & 19 \\
P3 & & & & & & & & & & 17 & $\mathbf{3 2}$ & $\mathbf{1 4}$ & 8 \\
P4 & & & & & & & & & $\mathbf{3 9}$ & $\mathbf{8 8}$ & 6 & 22 \\
P7 & & & & & & & & & &
\end{tabular}

Note. Attributes (A): 1. Learning Korean 2. Improving physical strength 4. Building a human network 7. Selfimprovement/Functional consequences (F): 1. Maintaining a friendship 3. Feeling physically better 5. A better understanding of Korea 7. Improving my ability 8. Building a positive image of me/Psychological consequences (P): 1. Feeling pleasure 3. Understanding others 4. A boost in confidence 7. Self-satisfaction/Values (V): 1. Happiness 3. A sense of accomplishment 4. Improving social skills. 5. The value of life; Strong linkages are represented in bold letters. 


\subsubsection{Bicultural Marginalization}

A-C linkage indicates escaping daily life and vital life energy (24 times) linked most frequently, followed by learning Korean and maintaining a friendship (13 times). F-P linkage represents relationship vital life energy and reducing anxiety (35 times) is the most substantial connection, followed by maintaining a friendship and feeling pleasure (20 times). P-V linkage shows reducing anxiety and a state of balance being linked the most frequently (44 times) (see Table 7).

Table 7. Implication Matrix of Leisure Activity Participants (Bicultural marginalization).

\begin{tabular}{cccccccccccc}
\hline & F1 & F2 & F3 & F5 & P1 & P2 & P3 & P5 & V1 & V2 & V3 \\
\hline A1 & $\mathbf{1 3}$ & 2 & 3 & 5 & & & & & & & \\
A2 & 1 & 4 & $\mathbf{9}$ & 0 & & & & & & & \\
A8 & 3 & $\mathbf{2 4}$ & $\mathbf{8}$ & 2 & & & & & & & \\
A9 & 1 & $\mathbf{1 2}$ & $\mathbf{1 2}$ & 0 & & & & & & & \\
F1 & & & & & $\mathbf{2 0}$ & $\mathbf{9}$ & $\mathbf{1 2}$ & 3 & & & \\
F2 & & & & & 5 & $\mathbf{3 5}$ & 2 & $\mathbf{1 5}$ & & & \\
F3 & & & & & $\mathbf{1 5}$ & $\mathbf{1 2}$ & $\mathbf{8}$ & 7 & & & \\
F5 & & & & & 1 & 2 & $\mathbf{8}$ & 1 & & & \\
P1 & & & & & & & & $\mathbf{2 3}$ & $\mathbf{1 1}$ & 4 \\
P2 & & & & & & & & & $\mathbf{1 1}$ & $\mathbf{4 4}$ & $\mathbf{8}$ \\
P3 & & & & & & & & & $\mathbf{1 3}$ & 4 & 5 \\
P5 & & & & & & & & & & \\
\hline
\end{tabular}

Note. Attributes (A): 1. Learning Korean 2. Improving physical strength 8. Escaping daily life 9. Relaxing/Functional consequences (F): 1. Maintaining a friendship 2. Vital life energy 3. Feeling physically better 5. Better understanding Korea/Psychological consequence (P): 1. Feeling pleasure 2. Reducing anxiety 3. Understanding others 5. Refreshing myself/Values (V): 1. Happiness 2. A state of balance 3. A sense of accomplishment: Strong linkages are represented in bold letters.

\subsection{Three Types of Hierarchical Value Maps Based on Acculturation}

An issue to be taken into account when building an HVM is where to determine the cut-off point. In this study, multiple cut-off levels by Pieters et al. [73] were chosen in order to find the one that led to the most informative and interpretable explanation and accounted for the most relationships among elements with a relatively small number of cells in the implication matrix. When it comes to the cut-off levels for this study, only a small portion of the more prominent relationships was accounted for, slightly lower than those suggested by Reynolds and Gutman [75]. However, previous laddering research mostly focused on products to better understand consumers $[45,76,77]$ or a specific place [78], while the respondents of this study are required to capture abstract thinking. Additionally, each respondent was able to choose one to three items for each level [75] so that responses were diverse and repeatedly mentioned. Therefore, it was necessary to determine cut-off points that produced a parsimonious and clear set of HVMs. Accordingly, each cut-off point on the acculturation type is configured at 22,24 , and 8 , respectively. Linkages with the frequency of above the cut-off points are shown on the HVM. The format for the HVM was suggested by Gengler et al. [79]; a circle illustrates each concept. The number of subjects mentioning a concept is represented on the graph by varying the size of the circle on the map, while the relative strength of association across concepts is represented by varying the width of the line connecting related concepts. The frequency of the links between concepts is indicated with the line of differing thicknesses, and thicker lines show strong relationships.

The HVMs for the three types of acculturation, with cut-off levels, presented the essence of these means-end chain linkages. For each acculturation type, the dominant chains represented by gray-filled circles and labeled using upper-case letters are linked by thicker arrows. First, the HVM of bicultural acceptance reflected their innermost thinking and desired psychological states. The overall analysis showed that international students have a strong motivation for "learning Korean" by participating in leisure activities, and they "improve their skills" through "learning Korean," which makes them "feel pleasure." The pleasure of participation led to reach the ultimate goal of "happiness." Addition- 
ally, they prefer "understanding Korean culture" as well as Korean language learning to improve their "better understanding of Korea" and "understanding others" through their participation in leisure activities. The "understanding others" help them achieve the ultimate value of "increasing social skills." When it comes to the associations, the attribute "learning Korean" was strongly associated with the functional consequence "improving my ability," which led to "feeling pleasure" and "happiness" for students. Heritage culture maintenance is a type that places a higher value on the heritage culture than the mainstream culture. They were found to participate in leisure activities for "self-improvement" and desire for "improving their ability." The functional consequences of leisure activities cause them to feel "self-satisfaction" and obtain "a sense of accomplishment" while studying in Korea. For other students, on the other hand, "learning Korean" through leisure activities, cause them to improve "better understanding of Korea" and help "understanding others." These positive functional and psychological consequences offer them the final value of "improving social skills" while staying in Korea. In terms of the association, the attribute "self-improvement" was strongly associated with "improving my ability," which in turn produced the psychological consequence "self-satisfaction" and "a sense of accomplishment." For those who are a type of bicultural marginalization, leisure activities offer the students "escaping daily life" and "vital life energy." The consequences resulting from the activities led to "reducing anxiety" and reaching "a state of balance." The psychological consequence "understanding others" no longer continues to reach the value level, which disclosed that the factor exceeded the cut-off point at the lower level but failed to obtain the frequency leading to a higher level (see Figure 1).

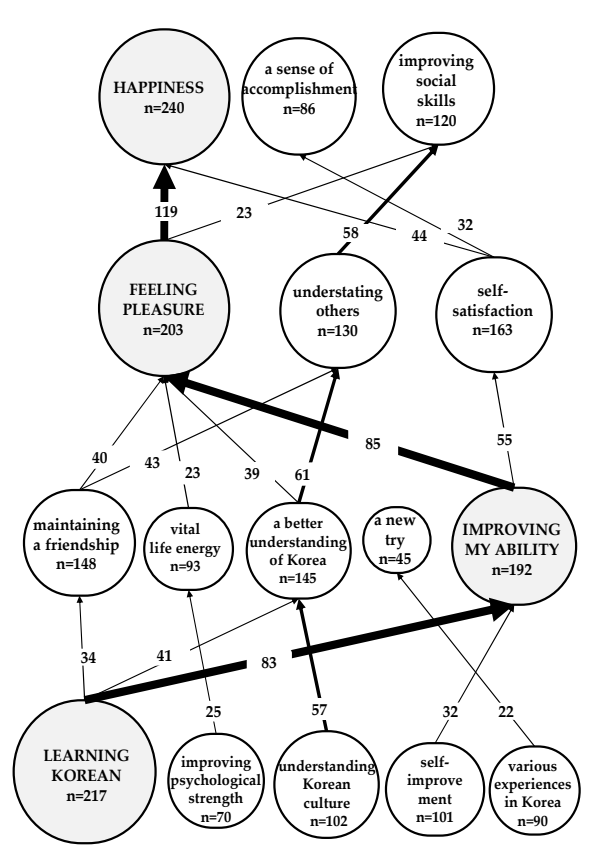

(a)

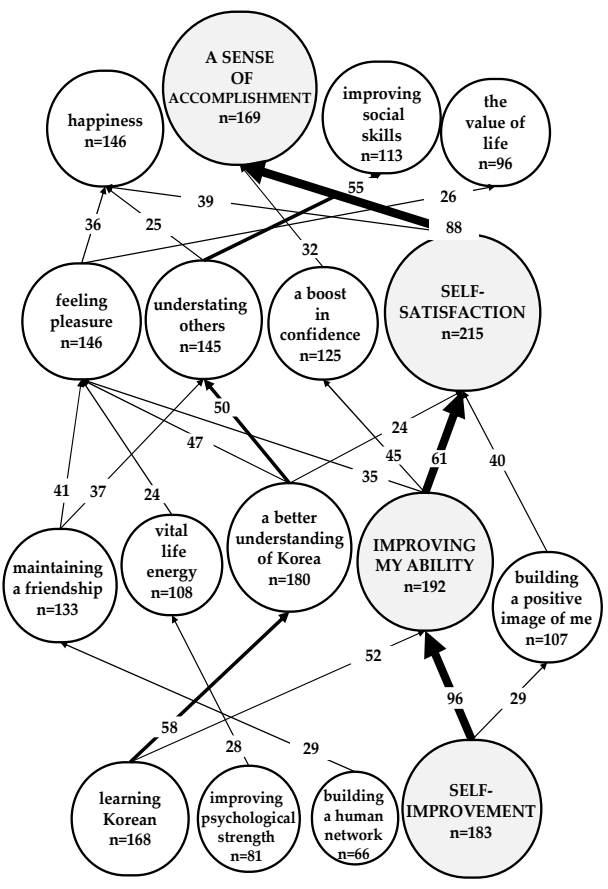

(b)

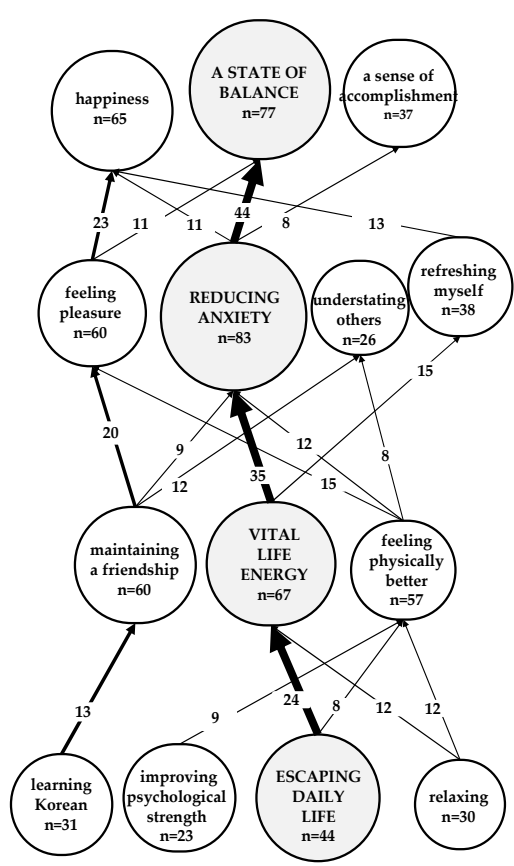

(c)

Figure 1. Hierarchical Value Maps based on Acculturation Types as: (a) Bicultural Acceptance $(n=171 /$ cut-off $=22)$; (b) Heritage Cultural Maintenance $(n=182 /$ cut-off $=24)$; (c) Bicultural Marginalization $(n=62 /$ cut-off $=8)$.

\section{Conclusions and Discussion}

\subsection{Conclusions}

Engagement in leisure activity can be used as an opportunity for personal achievement, not just for free time from the demands of work or duty. Participation in various leisure activities can affect the quality of life and provide the driving force that makes life more valuable to pursue happiness for college students [80]. The aim of this study is to use HVMs 
produced by an integrated approach of MEC and acculturation to explore personal values and understand a cognitive structure based on the level of acculturation for international students. These consequences can be utilized as a basis for positioning international students' leisure engagement. The results of this study illustrate the importance of activity participation for international students, indicating that the promotion of participation in leisure activities should be considered according to their acculturation status.

Even though the different types of cognitive structures were produced depending on acculturation types, this study identified an unexpected critical role of leisure for international students irrespective of acculturative level. In terms of the attributes of leisure activities, international student respondents valued the following attribute: learning Korean. The main property is similar to the study's adopted experiential learning theory to examine the role of leisure in socio-cultural adaptation [43], which identified experiential learning strategies to learn about the host culture as the significant cognitive factor. Thus, it appears that leisure plays a positive role in learning about the culture of the host country [2] In terms of consequences, international students believed that participation produced the following three consequences: maintaining a friendship, feeling pleasure, and understanding others. Of these consequences, maintaining a friendship, one of the functional consequences, had a strong association with a positive psychological state, feeling pleasure and understanding others. Consistent with this outcome, Lee et al. [13] have reported that engagement in leisure activities for international students provides opportunities for friendship formation. When it comes to it, international students hoped to experience happiness and s sense of accomplishment through leisure participation. These results support the cross-cultural study findings suggested by Ito et al. [4], demonstrating that personal happiness is associated with psychological and social leisure satisfaction among Canadian and Chinese students and psychological leisure satisfaction among Japanese students. These results suggest that different aspects of leisure satisfaction are associated with personal happiness differently across cultures.

Lastly, it is necessary to address the overarching question: the relationship between leisure and sustainability. It is widely believed that leisure contributes to coping with various life stressors, specifically immigration-related stressors [81]. However, the results of this study indicate that such positive relations vary on acculturation types; thus, the attributes, psychological/functional consequences of participating in leisure activities, and the ultimate value vary depending on how much more attached to Korean or heritage culture they are. For instance, high-acculturated students pursue happiness through leisure activities, while for low-acculturated students, leisure is to escape daily life and seek a state of balance. As Walker et al. [7] posited, "leisure practitioners could potentially learn from other comparable cultures how to help their clients experience the benefits of leisure." With the present findings, this study extends the knowledge to find a sustainable future for student mobility. Leisure can be considered a potential solution to the broader types of sustainability challenges addressed in international higher education. In order to make meaningful contributions, there is a need to identify and question how leisure is part of the problem and part of the solution for international students.

\subsection{Theoretical Implications}

Several salient implications can be derived from the findings of this study. The current research is one of the first to explore and produce international students' perceived meanings and values of leisure activities based on acculturation types. In order to analyze the leisure value attributes and formation process of leisure participants, both qualitative and quantitative approaches were utilized for means-end chain theory [82]. Overall, there is a dearth of leisure research that combines the two methods of laddering techniques, and only a few leisure value systems studies consist of stages of leisure attributes, consequences, and values using laddering techniques focused on international students. This combined research method has contributed to leisure value research by quantifying the laddering results and extending and validating the results of previous studies. Additionally, this 
study extended the cultural adaptation theory presented by Berry [27] to the domain of leisure studies, which suggests that a fuller understanding of the relationships between acculturation types and perceived leisure values can only be achieved in cultural contexts. The majority of previous studies that examined the acculturation for international students in Korea targeted Chinese students. Based on this prior research, this further study reports on respondents across six continents, including Northeast Asia, Southeast Asia, Central Asia, Europe, America, and Africa, using the sample's proportional allocation in stratified sampling followed sampling recommendations such as sampling from cultural zones, studying more than two cultures in the cross-cultural study [83].

In terms of acculturation types, the data analyses revealed this sample clustered into three groups which fell along a continuum from relatively higher attachment with heritage and Korean culture to comparatively lower attachment with both cultures. The score on both Korean and heritage cultural dimensions was high; heritage attachment was more significant on average, suggesting that attachment to heritage culture remains an essential part of overall cultural identity [84]. The results indicated that the attributes, consequences, and values of participation in leisure activities differ depending on the acculturation to Korean culture. Students with a high degree of acceptance of both native and Korean culture (bicultural acceptance) pursue happiness summarized as a combination of life satisfaction, the presence of positive mood, and the absence of negative mood [85]. Respondents engaged in cultural marginalization, which has low values of both Korean and native culture, and adopted a state of balance as an ultimate value. Respondents who are more inclined to maintain their native culture than Korean culture hope to experience a sense of accomplishment described as a reward for doing their best for valuable things beyond mere satisfaction [86]. Consequently, the results of this study suggest that leisure is a subjective experience reflecting an individual's emotional state or mood [87].

Additionally, ethnic diversity has increased substantially in many countries with the increased mobility of international students between countries. The findings obtained from prior studies on the leisure engagement of international students have mainly focused on the relationship between leisure participation and school adaptation or the impact of leisure activities to adopt hosting countries among international students. However, examining participants' inner thoughts and why international students participate in leisure, and what benefits they hope to gain from participation is rare. By integrating the means-end chain theory, this study's results provide researchers and practitioners with a comprehensive picture of how international students' cognitive structure is formed according to acculturation types. A combination of acculturation types and hierarchical value maps indicates the dominant A-C-V chains of leisure participants, enabling researchers to understand international students' inner thoughts and values.

\subsection{Practical Implications}

The findings of this research can provide insightful information on the managerial and organizational levels. Provision of cross-cultural training for leisure professionals might help improve their cultural sensitivity and understanding. Specifically, a finding is that that learning Korean is essential for international students studying in Korea; thus, organizations should develop cultural programs such as cultural tours, taekwondo (a Korean martial art), making kimchi, and creating an environment where students can adapt to college and Korean life through various experiences. In addition, opportunities should be provided for international students to participate in social volunteering activities with a local community, such as cultural sharing, counseling, encouraging opportunities to participate in leisure activities where they can study Korean culture in harmony with Koreans, which will be an effective way to gain social support from Korean society.

Additionally, regarding the values of leisure activity, this study found that a selfactualizing value [88] such as happiness and a sense of accomplishment is recognized as the essential value of international students. Regarding the experience of leisure values, organizations should consider having events such as speaking Korean or K-POP festivals 
for international students, thereby enabling them to gain a sense of accomplishment and feel proud of their work during their studies. This study shows that the international office of universities should provide support based on students' acculturation to adapt to international students. It is suggested that university staff attract students during the initial years of settlement to facilitate familiarization with leisure activities and overcome their settlement barriers resulting from acculturative stress. Consequently, the availability of some ethno-specific leisure services is required to better cater for those who are at an early stage of acculturation and those who may not want to become acculturated.

\subsection{Limitation and Future Research}

As with any research, this study contains certain limitations. The number of samples in this study was conducted with 415 international students, and adopted a stratified sampling. The students cannot represent a national culture; thus, the results may not be generalizable to international students studying in Korea. Nevertheless, this study has generated important findings utilizing an integrated approach of acculturation and MEC theory. The results of this study help raise the awareness of host university management and relevant organizations to review and support their service program for international students. To guide further inquiry, a two-fold approach is suggested with expanded research that: (1) proposes approaches to enhance cross-cultural leisure study; and (2) questions the relationship between leisure and sustainability. The first aim of future research should be to examine how racial and cultural factors intertwine to shape international students' behaviors in the different sub-cultural contexts. Samples should more precisely define the culture being studied and measure specific cultural dimensions as a verification method. Similarly, the samples are required to study specific leisure practices depending on socio-demographic variables such as gender, age, and length of residence. The sampling method in the future can be addressed by employing large numbers of cultures, which was a possibility of a statistical test of inference [89]. The second aim of future research should be to question to what extent and how leisure contributes to socio-cultural dimensions of sustainability. Communities contain people who are at different levels and stages of acculturation. Some are highly acculturated; some are less or not acculturated. These people undergo a continuous process of cultural change at different paces. Leisure professionals need to understand the leisure needs, interests, and constraints of their diverse populations to offer equitable leisure opportunities in multicultural societies. Faced with such challenges in society, leisure research should make stronger connections to other disciplines involved in research on sustainability to contribute to the emergence of broader social theories. Even though empirical research on the relationship between leisure and sustainability is scarce, a few cross-cultural leisure researches suggested ideas of sustainable leisure participation for international students. Different forms of knowledge were integrated to investigate cultural differences in leisure studies, such as Tsai et al.'s [90] affect valuation theory and the self-construal theory suggested by Kitayama et al. [91]. Consequently, leisure scholars should question their research and practices in a way that results in a better understanding of both what leisure does to alleviate sustainability issues and what it does to cause them [92].

To influence the sustainability challenges faced in society, it is necessary to identify and question how leisure is part of the problem or solution [93]. The themes identified in this study may serve as a benchmark to understand the influence of acculturation on the perception of leisure values of international students concerning sustainability in the future. Guided by the two-fold approach suggested in this study, leisure researchers should examine the relationship between leisure and sustainability and propose approaches to enhance sustainability in cross-cultural contexts.

Author Contributions: Conceptualization, N.L.; methodology, N.L.; software, N.L.; validation, B.S.K.; investigation, B.-S.K.; resources, N.L.; data curation, B.-S.K.; writing-original draft preparation, N.L.; writing—review and editing, B.-S.K.; visualization, N.L.; supervision, B.-S.K.; All authors have read and agreed to the published version of the manuscript. 
Funding: This research received no external funding.

Informed Consent Statement: Informed consent was obtained from all subjects involved in the study.

Data Availability Statement: The data are held with the authors.

Conflicts of Interest: The authors declare no conflict of interest.

\section{References}

1. Edginton, C.R.; Chen, P. Leisure as Transformation, 2nd ed.; Sagamore Publishing: Champaign, IL, USA, 2008 ; pp. 67-121.

2. Liu, H.; Da, S. The relationships between leisure and happiness-A graphic elicitation method. Leis. Stud. 2020, 39, 111-130. [CrossRef]

3. Malysheva, S. The Rehabilitation of Idleness: The Productionof New Values and Meanings for Leisure in the Late 19th and Early 20th Centuries; Gaidar Institute Press: Moscow, Russia, 2019; Volume 29, p. 147. [CrossRef]

4. Ito, E.; Walker, G.J.; Liu, H.; Mitas, O. A cross-cultural/national study of Canadian, Chinese, and Japanese university students' leisure satisfaction and subjective well-being. Leis. Sci. 2017, 39, 186-204. [CrossRef]

5. Walker, G.J.; Deng, J.; Chapman, R. Leisure attitudes: A follow-up study comparing Canadians, Chinese in Canada, and Mainland Chinese. World Leis. J. 2007, 49, 207-215. [CrossRef]

6. Deng, J.; Walker, G.J.; Swinnerton, G. Leisure attitudes: A comparison between Chinese in Canada and Anglo-Canadians. Leisure 2005, 29, 239-273. [CrossRef]

7. Walker, G.J.; Deng, J.; Dieser, R.B. Culture, self-construal, and leisure theory and practice. J. Leis. Res. 2005, 37, 77-99. [CrossRef]

8. Kuykendall, L.; Tay, L.; Ng, V. Leisure engagement and subjective well-being: A meta-analysis. Psychol. Bull. 2015, 141, 364. [CrossRef] [PubMed]

9. Zhang, J.; Zheng, Y. How do academic stress and leisure activities influence college students' emotional well-being? A daily diary investigation. J. Adolesc. 2017, 60, 114-118. [CrossRef] [PubMed]

10. Lu, C.Y.; Yeh, W.-J.; Chen, B.T. The study of international students' behavior intention for leisure participation: Using perceived risk as a moderator. J. Qual. Assur. Hospit. Tour. 2016, 17, 224-236. [CrossRef]

11. Kim, C.; Scott, D.; Oh, C.-O. Effects of acculturation, leisure benefits, and leisure constraints on acculturative stress and self-esteem among Korean immigrants. Soc. Leis. 2005, 28, 265-296. [CrossRef]

12. Li, M.Z.; Stodolska, M. Transnationalism, leisure, and Chinese graduate students in the United States. Leis. Sci. 2006, 28, 39-55. [CrossRef]

13. Lee, C.; Sung, Y.-T.; Zhou, Y.; Lee, S. The relationships between the seriousness of leisure activities, social support and school adaptation among Asian international students in the US. Leis. Stud. 2018, 37, 197-210. [CrossRef]

14. Zhou, Y.; Zhang, H.; Stodolska, M. Acculturative stress and leisure among Chinese international graduate students. Leis. Sci. 2018, 40, 557-577. [CrossRef]

15. Mak, A.S.; Buckingham, K. Beyond communication courses: Are there benefits in adding skills-based ExcelL ${ }^{\mathrm{TM}}$ socio-cultural training? Int. J. Intercult. Relat. 2007, 31, 277-291. [CrossRef]

16. Li, K.-C.; Sotiriadou, P.; Auld, C. An examination of the role of sport and leisure on the acculturation of Chinese immigrants. World Leis. J. 2015, 57, 209-220. [CrossRef]

17. Tsai, W. Social capital, strategic relatedness and the formation of intraorganizational linkages. Strateg. Manag. J. 2000, 21, 925-939. [CrossRef]

18. Afable-Munsuz, A.; Ponce, N.A.; Rodriguez, M.; Perez-Stable, E.J. Immigrant generation and physical activity among Mexican, Chinese \& Filipino adults in the US. Soc. Sci. Med. 2010, 70, 1997-2005.

19. Tsai, E.H. The influence of acculturation on perception of leisure constraints of Chinese immigrants. World Leis. J. 2000, 42, 33-42. [CrossRef]

20. Kim, J.; Suh, Y.I.; Kim, J. Identifying leisure constraints associated with acculturation among older Korean immigrants. Int. J. Qual. Stud. Health Well-being 2019, 14, 1655378. [CrossRef]

21. Christenson, O.D.; Zabriskie, R.B.; Eggett, D.L.; Freeman, P.A. Family acculturation, family leisure involvement, and family functioning among Mexican-Americans. J. Leis. Res. 2006, 38, 475-495. [CrossRef]

22. Kim, J.; Lee, H. The relationships among acculturation, self-esteem, and leisure participation of foreign workers in Korea. Int. J. Tour. Sci. 2010, 10, 45-60. [CrossRef]

23. Kim, J.H.; Heo, J.M.; Lee, C.S. Exploring the relationship between types of leisure activities and acculturation among Korean immigrants. Leis. Stud. 2016, 35, 113-127. [CrossRef]

24. Lin, C.F.; Fu, C.S. Cognitive implications of experiencing religious tourism: An integrated approach of means-end chain and social network theories. Int. J. Tour. Res. 2020, 22, 71-80. [CrossRef]

25. Wu, T.-C.; Lin, Y.-E.; Wall, G.; Xie, P.F. A spectrum of indigenous tourism experiences as revealed through means-end chain analysis. Tour. Manag. 2020, 76, 103969. [CrossRef]

26. Berry, J.W. Immigration, acculturation, and adaptation. Appl. Psychol. 1997, 46, 5-34. [CrossRef]

27. Berry, J.W. Acculturation and adaptation: A general framework. In Mental Health of Immigrants and Refugees; Holtzman, W.H., Ed.; Hogg Foundation for Mental Heatlh: Austin, TX, USA, 1990; pp. 90-102. 
28. Nguyen, H.H.; Messé, L.A.; Stollak, G.E. Toward a more complex understanding of acculturation and adjustment: Cultural involvements and psychosocial functioning in Vietnamese youth. J. Cross-Cultur. Psychol. 1999, 30, 5-31. [CrossRef]

29. Ha, J.-P.; Hums, M.A.; Greenwell, C.T. The impact of acculturation and ethnic identity on American football identification and consumption among Asians in the United States. Int. J. Sports Mark. Spons. 2014, 15, 47-64. [CrossRef]

30. Zhang, H.; Yan, L.; Lee, H.M.; Yang, Q. Social integration of lifestyle migrants: The case of Sanya snowbirds. Curr. Issues Tour. 2020, 23, 2825-2838. [CrossRef]

31. Barry, D.T. Development of a new scale for measuring acculturation: The East Asian Acculturation Measure (EAAM). J. Immigr. Health 2001, 3, 193-197. [CrossRef] [PubMed]

32. Ryder, A.G.; Alden, L.E.; Paulhus, D.L. Is acculturation unidimensional or bidimensional? A head-to-head comparison in the prediction of personality, self-identity, and adjustment. J. Pers. Soc. Psychol. 2000, 79, 49. [CrossRef]

33. Zea, M.C.; Asner-Self, K.K.; Birman, D.; Buki, L.P. The Abbreviated Multidimentional Acculturation Scale: Empirical validation with two Latino/Latina samples. Cultur. Divers. Ethn. Minor. Psychol. 2003, 9, 107. [CrossRef] [PubMed]

34. Testa, S.; Doucerain, M.M.; Miglietta, A.; Jurcik, T.; Ryder, A.G.; Gattino, S. The Vancouver Index of Acculturation (VIA): New evidence on dimensionality and measurement invariance across two cultural settings. Int. J. Intercult. Relat. 2019, 71, 60-71. [CrossRef]

35. Kim, H.J. A Comparative Study on the Acculturative Factors and Strategies of the Acculturative Level-Based International Students in Korea. Kor. Soc. Bilingual. 2017, 69, 51-79.

36. Cao, C.; Zhu, C.; Meng, Q. Predicting Chinese international students' acculturation strategies from socio-Demographic variables and social ties. Asian J. Soc. Psychol. 2017, 20, 85-96. [CrossRef]

37. Kim, J.; Park, S.-H.; Malonebeach, E.; Heo, J. Migrating to the East: A qualitative investigation of acculturation and leisure activities. Leis. Stud. 2016, 35, 421-437. [CrossRef]

38. Grund, A.; Brassler, N.K.; Fries, S. Torn between study and leisure: How motivational conflicts relate to students' academic and social adaptation. J. Educ. Psychol. 2014, 106, 242. [CrossRef]

39. Lehto, X.Y.; Cai, L.A.; Fu, X.; Chen, Y. Intercultural interactions outside the classroom: Narratives on a US campus. J. Coll. Stud. Dev. 2014, 55, 837-853. [CrossRef]

40. Choi, S.-H.; Jang, H. How Can Marriage Immigrants Contribute to the Sustainability of the Host Country? Implication from the Leisure and Travel Patterns of Vietnamess Women in South Korea. Sustainability 2021, 13, 1039. [CrossRef]

41. Stodolska, M.; Alexandris, K. The role of recreational sport in the adaptation of first generation immigrants in the United States. J. Leis. Res. 2004, 36, 379-413. [CrossRef]

42. Kim, S.H.; Kim, Y.I.; Tsai, I.J. A Study of Differences Leisure Activities on Acculturation Types and the Effect of Leisure Activities on Leisure Satisfaction: Focusing on Internationally Married Female Immigrants. J. Tour. Sci. 2012, 36, 189-210.

43. Zhang, H.; Zhou, Y.; Stodolska, M. Socio-cultural adaptation through leisure among Chinese international students: An experiential learning approach. Leis. Sci. 2018, 1-20. [CrossRef]

44. Lian, X.P.; Yang, M.H. The Effect of School Adaptation Stress and Leisure-Time Exercise on School Life Maladjustment among Chinese Students in Korea. J. Mar. Sport Stud. 2016, 6, 37-55. [CrossRef]

45. Gutman, J. A means-end chain model based on consumer categorization processes. J. Mark. 1982, 46, 60-72. [CrossRef]

46. Lin, C.-F.; Yeh, M.-Y. Means-end chains and cluster analysis: An integrated approach to improving marketing strategy. J. Target. Measur. Anal. Mark. 2000, 9, 20-35. [CrossRef]

47. Walker, B.A.; Olson, J.C. Means-end chains: Connecting products with self. J. Bus. Res. 1991, 22, 111-118. [CrossRef]

48. Lin, C.-S.; Jeng, M.-Y.; Yeh, T.-M. The elderly perceived meanings and values of virtual reality leisure activities: A means-end chain approach. Int. J. Environ. Res. Public Health 2018, 15, 663. [CrossRef]

49. McDonald, S.; Thyne, M.; McMorland, L.-A. Means-end theory in tourism research. Ann. Tour. Res. 2008, 35, 596-599. [CrossRef]

50. López-Mosquera, N.; Sánchez, M. The influence of personal values in the economic-use valuation of peri-urban green spaces: An application of the means-end chain theory. Tour. Manag. 2011, 32, 875-889. [CrossRef]

51. Jiang, S.; Scott, N.; Tao, L.; Ding, P. Chinese tourists' motivation and their relationship to cultural values. Anatolia 2019, 30, 90-102. [CrossRef]

52. Hong, M.H.; Won, Y.S. Analysis on Yoga Practitioners' Value System. Kor. J. Soc. Sport 2006, 19, 155-170. (In Korean)

53. Kim, Y.J. An Analysis on Leisure Value Systems Applying Means-end Chain(MEC). Kor. J. Leis. Rec. Park 2017, 41, 55-73. [CrossRef]

54. Grunert, K.G.; Valli, C. Designer-made meat and dairy products: Consumer-led product development. Livest. Prod. Sci. 2001, 72, 83-98. [CrossRef]

55. Celenk, O.; Van de Vijver, F.J. Assessment of acculturation: Issues and overview of measures. ORPC 2011, 8, 1-22. [CrossRef]

56. Hinkle, D.N. The Change of Personal Constructs from the Viewpoint of a Theory of Construct Implications. Ph.D. Thesis, Ohio State University, Columbus, OH, USA, 1965.

57. Tey, Y.S.; Arsil, P.; Brindal, M.; Teoh, C.T.; Lim, H.W. Motivations underlying consumers' preference for farmers' markets in klang valley: A means-end chain approach. Sustainability 2017, 9, 1958. [CrossRef]

58. Zanoli, R.; Naspetti, S. Consumer motivations in the purchase of organic food: A means—End approach. Br. Food J. 2002, 104, 643-653. [CrossRef] 
59. Sorenson, D.; Henchion, M. Understanding consumers' cognitive structures with regard to high pressure processing: A means-end chain application to the chilled ready meals category. Food Qual. Prefer. 2011, 22, 271-280. [CrossRef]

60. Grunert, K.G.; Grunert, S.C. Measuring subjective meaning structures by the laddering method: Theoretical considerations and methodological problems. Int. J. Res. Mark. 1995, 12, 209-225. [CrossRef]

61. Russell, C.G.; Busson, A.; Flight, I.; Bryan, J.; Van Pabst, J.V.L.; Cox, D.N. A comparison of three laddering techniques applied to an example of a complex food choice. Food Qual. Prefer. 2004, 15, 569-583. [CrossRef]

62. Russell, C.; Cox, D. Understanding middle-aged consumers' perceptions of meat using repertory grid methodology. Food Qual. Prefer. 2004, 15, 317-329. [CrossRef]

63. Botschen, G.; Thelen, E. Hard versus soft laddering: Implications for appropriate use. New Dev. App. Consum. Behav. Res. 1998, 321-339. [CrossRef]

64. Hofstede, F.T.; Audenaert, A.; Steenkamp, J.-B.E.; Wedel, M. An investigation into the association pattern technique as a quantitative approach to measuring means-end chains. Int. J. Res. Mark. 1998, 15, 37-50. [CrossRef]

65. Grunert, K.G.; Beckmann, S.C.; Sørensen, E. Means-end chains and laddering: An inventory of problems and an agenda for research. In Understanding Consumer Decision Making: The Means-End Approach to Marketing Strategy; Olson, J.C., Reynolds, T.J., Eds.; Erlbaum: Mahwah, NJ, USA, 2001; pp. 63-90.

66. Johnson, M.D.; Herrmann, A.; Huber, F.; Gustafsson, A. An Introduction to Quality, Satisfaction, and Retention-Implications for the Automotive Industry. In Customer Retention in the Automotive Industry: Quality, Satisfaction and Loyalty; Johnson, M.D., Herrmann, A., Huber, F., Gustafsson, A., Eds.; Gabler Verlag: Wiesbaden, Germany, 1997; pp. 1-17. [CrossRef]

67. Reynolds, T.J.; Dethloff, C.; Westberg, S.J. Advancements in Laddering, Understanding Consumer Decision Making: The Means-End Approach to Marketing and Advertising Strategy; Lawrence Erlbaum Associates Publishers: Mahwah, NJ, USA, 2001; pp. 91-118.

68. Back, H.C.; Park, C.H.; Jang, S.Y.; Kim, J.H. Stakeholder's Valuation of Public PMO System Using Laddering. Kor. Soc. Sim. 2015, 24, 127-136. [CrossRef]

69. Henneberg, S.C.; Gruber, T.; Reppel, A.; Ashnai, B.; Naudé, P. Complaint management expectations: An online laddering analysis of small versus large firms. Ind. Mark. Manag. 2009, 38, 584-598. [CrossRef]

70. Igbaria, M.; Iivari, J.; Maragahh, H. Why do individuals use computer technology? A Finnish case study. Inf. Manag. 1995, 29, 227-238. [CrossRef]

71. Gim Chung, R.H.; Kim, B.S.; Abreu, J.M. Asian American multidimensional acculturation scale: Development, factor analysis, reliability, and validity. Cultur. Divers. Ethn. Minor Psychol. 2004, 10, 66. [CrossRef] [PubMed]

72. Reynolds, T.J.; Olson, J.C. Understanding Consumer Decision Making: The Means-End Approach to Marketing and Advertising Strategy, 1st ed.; Psychology Press: New York, NY, USA, 2001. [CrossRef]

73. Pieters, R.; Baumgartner, H.; Allen, D. A means-end chain approach to consumer goal structures. Int. J. Res. Mark. 1995, 12, 227-244. [CrossRef]

74. Han, H.C.; Cho, M.S.; Oh, J.S.; Seo, J.M. Relationship between the HVM and Cut-Off Level of Means-End Chain. J. Kor. Contents Assoc. 2011, 11, 414-427. [CrossRef]

75. Reynolds, T.J.; Gutman, J. Laddering theory, method, analysis, and interpretation. J. Advert. Res. 1988, $28,11-31$.

76. Gengler, C.E.; Reynolds, T.J. Consumer understanding and advertising strategy: Analysis and strategic translation of laddering data. J. Advert. Res. 1995, 35, 19-34.

77. Guenzi, P.; Troilo, G. Developing marketing capabilities for customer value creation through Marketing-Sales integration. Indu. Market. Manag. 2006, 35, 974-988. [CrossRef]

78. Klenosky, D.B.; Gengler, C.E.; Mulvey, M.S. Understanding the factors influencing ski destination choice: A means-end analytic approach. J. Leis. Res. 1993, 25, 362-379. [CrossRef]

79. Gengler, C.E.; Klenosky, D.B.; Mulvey, M.S. A Note on the Representation of Means-End Study Results; Working Paper; Rutgers University: Camden, NJ, USA, 1992.

80. Shim, S.S. Effects of Leisure Motivation on Leisure Satisfaction and Quality of Life in University Students. J. Sports Leis. Stud. 2016, 65, 439-450. [CrossRef]

81. Doherty, A.; Taylor, T. Sport and physical recreation in the settlement of immigrant youth. Leisure 2007, 31, 27-55. [CrossRef]

82. Jiang, S.; Scott, N.; Ding, P. Motivations of experienced leisure travellers: A means-end chain study on the Chinese outbound market. J. Vacat. Mark. 2019, 25, 225-238. [CrossRef]

83. Boehnke, K.; Lietz, P.; Schreier, M.; Wilhelm, A. Sampling: The selection of cases for culturally comparative psychological research In Cross-Cultural Research Methods in Psychology; Matsumoto, D., Van de Vijver, F.J.R., Eds.; Cambridge University Press: New York, NY, USA, 2011; pp. 101-129. [CrossRef]

84. Stonefish, T.; Kwantes, C.T. Values and acculturation: A Native Canadian exploration. Int. J. Intercult. Relat. 2017, 61, 63-76. [CrossRef]

85. Ryan, R.M.; Deci, E.L. On happiness and human potentials: A review of research on hedonic and eudaimonic well-being. Annu. Rev. Psychol. 2001, 52, 141-166. [CrossRef] [PubMed]

86. Keyes, C.L.; Shmotkin, D.; Ryff, C.D. Optimizing well-being: The empirical encounter of two traditions. J. Pers. Soc. Psychol. 2002, 82, 1007. [CrossRef]

87. Neulinger, J. The psychology of leisure: Research approaches to the study of leisure. Springfield 1974, 11, 295-306. [CrossRef] 
88. Stepanova, O.P.; Gridneva, S.V.; Menshikov, P.V.; Kassymova, G.K.; Tokar, O.V.; Merezhnikov, A.P.; Arpentieva, M.R. Valuemotivational sphere and prospects of the deviant behavior. Int.J. Educ. Inf. Tech. 2018, 12, 142-148.

89. Munroe, R.L.; Munroe, R.H. Results of comparative field studies. Behav. Sci. 1991, 25, 23-54. [CrossRef]

90. Tsai, J.L. Ideal affect: Cultural causes and behavioral consequences. Perspect. Psychol. Sci. 2007, 2, 242-259. [CrossRef]

91. Kitayama, S.; Duffy, S.; Uchida, Y. Self as cultural mode of being. In Handbook of Cultural Psychology; Kitayama, S., Cohen, D., Eds.; Guilford Press: New York, NY, USA, 2007; pp. 136-174.

92. Glover, T.D. Leisure research for social impact. J. Leis. Res. 2015, 47, 1-14. [CrossRef]

93. Vaugeois, N.; Parker, P.; Yang, Y. Is leisure research contributing to sustainability? A systematic review of the literature. Leisure 2017, 41, 297-322. [CrossRef] 